PUBLIC HEALTH RESEARCH

\title{
Coping Strategies in Children of Parents Deceased from Cancer and Children of Parents Healed from Cancer
}

\author{
Ghorban Hemati Alamdarloo, ${ }^{1 *}$ Shahram Moradi, ${ }^{2}$ Marziyeh Gholami, ${ }^{3}$ Zahra Nazari, ${ }^{4}$ and Parvin Amiri ${ }^{4}$ \\ ${ }^{1}$ Special Education Department, School of Education \& Psychology, Shiraz University, Shiraz, Iran. \\ ${ }^{2}$ Department of pedagogy, Religion, and Social Studies, Western Norway University of Applied Sciences, Bergen, \\ Norway. \\ ${ }^{3}$ Special Education Department, School of Psychology \& Education, Allameh Tabataba'i University, Tehran, \\ Iran. \\ ${ }^{4}$ Special Education Department, School of Education \& Psychology, Shiraz University, Shiraz, Iran. \\ *For reprint and all correspondence: Ghorban Hemati Alamdarloo, Special Education Department, School of \\ Education \& Psychology, Shiraz University, Eram Square, Shiraz, Iran. \\ E-mail: ghemati@shirazu.ac.ir \\ Phone: +98-711-6134654
}

ABSTRACT

\begin{tabular}{ll}
\hline Introduction & This study aimed to compare coping strategies in children of parents deceased \\
& from cancer and children of parents healed from cancer in the city of Shiraz, \\
Iran. & One-hundred and fifteen people [58 children of parents healed from cancer and \\
Methods & 57 children of parents deceased from cancer] were recruited in this study via a \\
& convenience sampling method. Coping Inventory for Stressful Situations was \\
& used to measure different types of coping strategies [task-oriented coping \\
& strategy, emotion-oriented coping strategy, and avoidance coping strategy]. \\
& The results showed that the children of parents healed from cancer used task- \\
& oriented coping strategy significantly more than children of parents deceased \\
from cancer. Moreover, the results showed that the use of emotion-oriented \\
coping strategy in children of parents deceased from cancer was significantly \\
more than children of parents healed from cancer. No significant difference \\
manclusions \\
was observed between the two groups in the use of avoidance coping. \\
This study highlights the importance of coping strategies in families with a \\
cancer parent which demands the importance of teaching appropriate coping \\
strategies in order to reduce the adverse consequence of cancer in the family. \\
Coping Strategies - Children - Parents - Cancer.
\end{tabular}

Article history

Received: 25 May 2021

Accepted: 8 August 2021

Published: 1 September 2021 


\section{INTRODUCTION}

Cancer is the third leading cause of death in Iran. ${ }^{1}$ Despite advances in diagnosis and treatment, cancer has a higher risk of mortality than other diseases due to uncertainty about the effectiveness of treatment. ${ }^{2}$ About $22.4 \%$ of cancers occur in people between the ages of 21 and 55. These years are the years of fertility and childbearing, so a significant number of people with cancer in these age range most probably have children. Cancer and its treatment pose unique challenges for people with children than those people with cancer, but without children. ${ }^{3}$ Diagnosis and treatment of cancer are very invasive, which almost are associated with depression and anxiety, not only for the person with cancer but also for their families. Diagnosing cancer leads to feelings of insecurity, loss of personal control, and feelings of helplessness. ${ }^{4}$

Children whose parents have cancer may have difficulties in their emotional, social, cognitive, behavioral, and physical functioning. Chiaos in the family usually arise in the early stages of cancer diagnosis; however, health challenges and psychosocial concerns may persist even after the treatment of cancer is over. ${ }^{3,5}$

Coping with a chronic, long-term, progressive illness is complex and challenging. Coping is defined as "the constant change in [one's] behavior and cognition to cope with additional demands that are beyond [one's] competence." Coping is an important factor that affects people's emotional and behavioral response to stress. ${ }^{6}$ Coping strategies can be divided into task-oriented coping, emotionoriented coping and avoidance coping. Taskoriented coping refers to the use of problem-solving and information to change stressful situations. Emotion-oriented coping is defined as the attempt to reduce stress through emotional reactions [e.g., selfblame, depression, and anger] or rumination. ${ }^{7}$ Avoidance coping refers to the use of distraction, deviation, and retreat from behaviors to prevent stress. ${ }^{8}$ Coping strategies is closely related to body and mind health. In general, problem-oriented coping is associated with greater happiness, while emotion-oriented coping and avoidance coping are usually associated with unhealthy psychological phenomena. ${ }^{6}$

Most cancer research focuses on coping strategies used by patients. Few studies have been done on coping strategies for children of parents with cancer. It is important to have knowledge to plan and provide care programs that will help the children of these families' cope with the effects of cancer. The present study was conducted to compare coping strategies in children of parents deceased from cancer and children of parents healed from cancer to answer the following question: is there a significant difference between children of parents deceased from cancer and children of parents healed from cancer in terms of coping strategies?

\section{METHODS}

Population, sample, and sampling method The present study is a causal-comparative design and statistical population included all children of parents deceased from cancer and children of parents healed from cancer in the city of Shiraz, Iran. The sample consisted of 115 people [ 58 children of parents healed from cancer, 57 children of parents deceased from cancer]. Subjects were selected by convenience sampling method. The data were collected in the city of Shiraz during the year of 2020. In order to select the children of parents healed from cancer, we referred to "Atieh Sazan Hafez Insurance Center" [an insurance center dedicated to cancer patients which provides services to cancer patients as long as they are under treatment] and from the Atieh Sazan Hafez Insurance Center archives, the files of people healed from cancer were selected and their children were contacted and asked to participate in the research if they wished. In this way, 58 children of parents healed from cancer completed the Coping Inventory for Stressful Situations [CISS-21]. To select the children of parents deceased from cancer, "Amir Hospital "[a hospital dedicated to cancer patients under very serious condition and many of them die in this hospital]. To select the children of parents deceased from cancer, we referred to Amir Hospital and from the hospital archives, the files of people who had died due to cancer were selected and their children were contacted and asked to participate in the research if they wished. In this way, 57 children of parents deceased from cancer completed the CISS21. The inclusion criteria for entering the research were having a parent healed from cancer and deceased parents due to cancer, aged above 20 and him/her patients having no additional diseases other than cancer and signing the consent form for participation in the research.

The sample characteristics of the children of parents deceased from cancer and children of parents healed from cancer are presented in Table 1. There were no significant differences between groups in terms of the mean age, gender, birth order, family size, educational level, working status, divorced/separated status, death of spouse, life satisfaction, and family income (Table 1). 
Table 1 Sample characteristics for children of parents deceased from cancer, and children of parents healed from cancer

\begin{tabular}{|c|c|c|c|}
\hline & $\begin{array}{l}\text { Children of parents deceased } \\
\text { from cancer }[\mathrm{n}=57]\end{array}$ & $\begin{array}{l}\text { Children of parents healed } \\
\text { from cancer }[\mathrm{n}=58]\end{array}$ & Sig. \\
\hline Mean age [years] [SD] & $29.75[10.33]$ & $29.86[10.83]$ & $P \geq .05$ * \\
\hline Range [years] & $20-65$ & $20-62$ & $P \geq .05$ \\
\hline Male [female] & $23[34]$ & 18 [40] & $P \geq .05$ \\
\hline Birth order [SD] & $2.82[1.72]$ & $2.93[1.67]$ & $P \geq .05$ \\
\hline Family size [SD] & $6.68[2.11]$ & $6.09[1.65]$ & $P \geq .05$ \\
\hline $\begin{array}{l}\text { educational level }[\%]:<12 \\
\text { years[> } 12 \text { years] }\end{array}$ & 40.35 [59.65] & 36.21 [63.79] & $P \geq .05$ \\
\hline $\begin{array}{l}\text { Working status [\%]: working } \\
\text { [nonworking] }\end{array}$ & $35.1[64.9]$ & 37.9 [62.1] & $P \geq .05$ \\
\hline Divorced/separated [\%] & 1.75 & 3.4 & $P \geq .05$ \\
\hline Death of spouse [\%] & 1.75 & 3.4 & $P \geq .05$ \\
\hline $\begin{array}{l}\text { Satisfaction of life[\%]: } \\
\text { satisfying [no satisfying] }\end{array}$ & 98.1 [1.9] & $98.3[1.7]$ & $P \geq .05$ \\
\hline 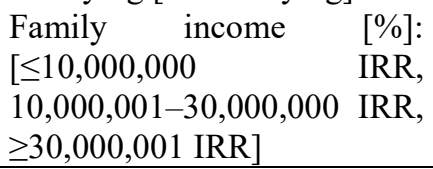 & {$[0,49.1,50.9]$} & {$[1.7,41.4,56.9]$} & $P \geq .05$ \\
\hline
\end{tabular}

Instrument

Coping Inventory for Stressful Situations [CISS-21] CISS-2 1 designed by Endler and Parker .9, 10 CISS21 is a self-report measure of general coping strategies. It is a shortened version of CISS-48 and has 21 items with three subscales: emotion-oriented coping [e.g. 'Become very upset'], task-oriented coping [e.g. "Work to understand the situation'] and avoidance coping [e.g. "Visit a friend"']. Each scale consists of 7 items. ${ }^{10}$ The participants rate each item on a five-point Likert scale [1= "not at all" to $5=$ "very much" $]$ to determine which coping strategies they use for different stressful situations. Subscale scores range from 7 to 35 , with higher scores indicating a preference for the use of a particular coping style. The CISS-21 has high internal consistencies for all the three subscales, and also has a good factor structure in samples from USA, ${ }^{11}$ the Netherlands, ${ }^{12}$ and Turkey. ${ }^{13}$ The Cronbach's alpha for CISS-21 in this study was 0.89 . It should be noted that the participants were asked to complete the paper and pencil version of CISS-21 individually at Atieh Sazan Hafez Insurance Center and Amir Hospital, and it took them about 10 minutes to complete it.

Ethical Considerations

Children of parents deceased from cancer and children of parents healed from cancer gave consent for their participation in this study. The participants were aware of the purpose of the study and they had the right to leave the study at any time if they wished so. The participants were also assured that all their information would remain confidential. The ethical review board of the Shiraz University approved the study.

\section{RESULTS}

Table 2 presents the scores of coping strategies subscales in children of parents deceased from cancer and children of parents healed from cancer.

Table 2 Mean and standard deviation of coping strategies' subscales in two groups

\begin{tabular}{lcccc}
\hline Groups & $\begin{array}{c}\text { Children of parents deceased } \\
\text { from cancer }[\mathrm{n}=57]\end{array}$ & \multicolumn{2}{c}{$\begin{array}{c}\text { Children of parents healed from } \\
\text { cancer [n=58] }\end{array}$} \\
\hline Dependent Variable & $M$ & $S D$ & $M$ & $S D$ \\
Task-oriented Coping & 20.07 & 5.15 & 24.52 & 3.88 \\
Emotion-oriented Coping & 26.59 & 4.15 & 22.36 & 5.18 \\
Avoidance Coping & 27.21 & 4.12 & 27.31 & 4.19 \\
\hline
\end{tabular}

As shown in Table 2, a significant difference between the mean scores of coping strategies subscales of the two groups were observed. A multivariate analysis of variance [MANOVA] was conducted to evaluate the source of this difference between groups. Before performing the MANOVA, the Levin test was first used to determine the homogeneity of variances, but this test was not significant for any of the variables $[P \geq 0.05]$. As a result, the use of MANOVA is possible. Moreover, 
the homogeneity of variance and covariance matrices was examined by the Box's M Test. Results showed that the Box's M value was not significant $[P \geq 0.05]$, and consequently the homogeneity between covariates was established. It is worth noting that the results of Kolmogorov-Smirnov test showed that the distribution of data in all variables was normal $[P>0.05]$. The results of MANOVA are presented in Table 3.

Table 3 The results of MANOVA for coping strategies' subscales in two groups

\begin{tabular}{lrrrrr}
\hline Dependent Variable & Sum of Squares & Df & Mean Square & \multicolumn{1}{c}{ F } & \multicolumn{1}{c}{ Sig. } \\
\hline Task-oriented Coping & 568.5284 & 1 & 568.5284 & 27.429 & 0.001 \\
Emotion-oriented Coping & 515.458 & 1 & 515.458 & 23.326 & 0.001 \\
Avoidance Coping & 0.286 & 1 & 0.286 & 0.017 & 0.898
\end{tabular}

As you can see in the table 3, the effect of the group on the dependent variable of task -oriented coping is significant $[\mathrm{F}=27.49, \mathrm{P}<0.001]$. This means that the use of task- oriented coping strategy in children of parents healed from cancer significantly more than children of parents deceased from cancer $[\mathrm{P}<0.001]$. Moreover, the effect of the group on the dependent variable of emotion-oriented coping is significant $[\mathrm{F}=23.236, \mathrm{P}<0.001]$. This means that the use of emotion-oriented coping strategy in the children of parents deceased from cancer significantly more than the children of parents healed from cancer $[\mathrm{P}<0.001]$. Moreover, as can be seen in the table 3, the effect of the group on the avoidance coping is not significant $[\mathrm{F}=0.017$, $\mathrm{P}>0.05]$. This means that there is no significant difference between the two groups in terms of avoidance coping strategy $[\mathrm{P}>0.05]$.

\section{DISCUSSION}

The results of the present study showed that children of parents healed from cancer used more taskoriented coping approach than children of parents deceased from cancer. This finding is consistent with Siciliano et al. ${ }^{14}$ and Kershaw et al. ${ }^{15}$ who showed that a task-oriented coping style put focus on problem definition, planning, generating alternative solutions, and selection of alternative options and action. Task-oriented coping tries to control and solve problems which is used in situations where the individual evaluates the situation as a changeable situation. ${ }^{16}$ Using a taskoriented coping strategy, people invest some of their time and energy in planning and implementing challenges in their family to easily fulfill their role responsibilities. Children of parents healed from cancer use problem-solving coping strategies to be able to play their role properly in front of parents. Psychological capital enables people to cope better and more productively in the face of stressful situations, to experience less stress, and to have higher abilities in the face of adversity, to gain a clear view of them, and to be less affected by daily events. ${ }^{2}$ Therefore, it can be argued that children of parents healed from cancer use strategies such as accepting responsibility and planning a problem to be able to support their parents. ${ }^{4}$
The findings also showed that the use of emotion-oriented coping in children of parents deceased from cancer was significantly higher than the children of parents healed from cancer. This finding is consistent with the findings of de Wit et al. ${ }^{7}$, Hanks et al. ${ }^{17}$ and Lindqvist et al. ${ }^{18}$ Explaining this finding, it can be argued that people with an emotion-oriented coping strategy believe that nothing can be done about stressors, and this strategy is often used in situations where people cannot change the prevailing environmental conditions. ${ }^{16}$ People who use emotion-oriented coping strategies have a lower perception of adequacy in dealing with different aspects of the situation. ${ }^{18}$ As a result, people feel they can't do anything about the situation. There is ample evidence that under certain circumstances, especially in cases where useful work cannot be done to change the situation, rational efforts to solve problems may not yield positive results; emotionally focused efforts are the best choice to deal with. ${ }^{19}$ Therefore, it can be said that children who have lost their parents because they cannot change the situation, choose emotion-oriented coping strategies.

Another finding of this study showed that there was no significant difference between the two groups in using the avoidance strategy. Explaining this finding, it can be argued that avoidance-based coping responses were associated with increased psychological distress ${ }^{20}$ and were associated with weaker outcomes. ${ }^{21}$ Using the avoidance coping strategy, the person tried to avoid stressful situations. People may hope that only time can solve the problem. ${ }^{16}$ In such situations, they may interact with others or engage in other activities, thereby gaining benefits. ${ }^{7}$ In fact, the avoidance coping strategy may have had benefits for both groups. Probably for this reason, there is no significant difference between the two groups in terms of avoidance coping strategy.

\section{CONCLUSIONS}

One of the limitations of this study was the small sample, the sample was not matched based on age and sex due to the availability of the sample. This study recommended the following: use of stress and 
emotion management training for children of cancer parents, group interventions for children of cancer patients to make them aware of other children's problems and how to deal with stress, teaching effective coping strategies to children of cancer parents, providing post-traumatic services for children of cancer parents and post-mortem counseling services to reduce children's self-blame.

\section{ACKNOWLEDGMENT}

Sincere thanks to the children of parents deceased from cancer and children of parents healed from cancer in Shiraz who participated in this study.

Declaration of interest statement

The author(s) declared no potential conflicts of interest with respect to the research, authorship, and/or publication of this article.

\section{REFERENCES}

1. Goli F, Scheidt CE, Gholamrezaei A, Farzanegan M. The role of locus of control and attributional style in coping strategies and quality of life among Iranian breast cancer and colorectal cancer patients: a pilot study. International Journal of Body, Mind and Culture. 2014;1[1]:65-72.

2. Akbari H, Akbari ME. The comparison of three components of breast cancer in females with cancer and healthy ones: coping styles, psychological capital, and patience. Multidisciplinary Cancer Investigation. 2018; 2(3):23-9.

3. Weaver KE, Rowland JH, Alfano CM, McNeel TS. Parental cancer and the family: a population-based estimate of the number of US cancer survivors residing with their minor children. Cancer. 2010;116(18):4395401.

4. Roesch SC, Adams L, Hines A, Palmores A, Vyas P, Tran C, Pekin S, Vaughn AA. Coping with prostate cancer: a meta-analytic review. Journal of behavioral medicine. 2005 Jun 1;28(3): 281-93.

5. Welch AS, Wadsworth ME, Compas BE. Adjustment of children and adolescents to parental cancer: Parents' and children's perspectives. Cancer: Interdisciplinary International Journal of the American Cancer Society. 1996; 77(7):1409-18.

6. Li C, Liu Q, Hu T, Jin X. Adapting the short form of the Coping Inventory for Stressful Situations into Chinese. Neuropsychiatric disease and treatment. 2017; 13:1669.

7. de Wit J, Bakker LA, van Groenestijn AC, Baardman JF, van den Berg LH, VisserMeily JM, SchrÖder CD. Psychological distress and coping styles of caregivers of patients with amyotrophic lateral sclerosis: a longitudinal study. Amyotrophic Lateral
Sclerosis and Frontotemporal Degeneration. 2019; 20(3-4):235-41.

8. Imran S, MacBeth A, Quayle E, Chan SW. Adaptation of the Coping Inventory for Stressful Situations [Short Form] for Pakistani Adolescents. J Psychol Psychother. 2020; 10(375):2161-0487.

9. Endler NS, Parker JD. Assessment of multidimensional coping: Task, emotion, and avoidance strategies. Psychological assessment. 1994; 6(1):50.

10. Endler NS, Parker JD. Assessment of multidimensional coping: Task, emotion, and avoidance strategies. Psychological assessment. 1994;6(1):50.

11. Cohan SL, Jang KL, Stein MB. Confirmatory factor analysis of a short form of the coping inventory for stressful situations. Journal of clinical psychology. 2006; 62(3):273-83.

12. Calsbeek H, Rijken M, Henegouwen GP, Dekker J. Factor structure of the Coping Inventory for Stressful Situations [CISS-21] in adolescents and young adults with chronic digestive disorders. The Social Position of Adolescents and Young Adults with Chronic Digestive Disorders. Utrecht: NIVEL. 2003.

13. Boysan M. Validity of the coping inventory for stressful situations-short form [CISS-21] in a non-clinical Turkish sample. Dusunen Adam The Journal of Psychiatry and Neurological Sciences. 2012; 25(2):101.

14. Siciliano M, Santangelo G, Trojsi F, Di Somma $\mathrm{C}$, Patrone $\mathrm{M}$, Femiano $\mathrm{C}$, Monsurrò MR, Trojano L, Tedeschi G. Coping strategies and psychological distress in caregivers of patients with Amyotrophic Lateral Sclerosis [ALS]. Amyotrophic Lateral Sclerosis and Frontotemporal Degeneration. 2017;18(5-6):367-77.

15. Kershaw T, Northouse L, Kritpracha C, Schafenacker A, Mood D. Coping strategies and quality of life in women with advanced breast cancer and their family caregivers. Psychology \& Health. 2004;19(2):139-55.

16. Rantanen M, Mauno S, Kinnunen U, Rantanen J. Do individual coping strategies help or harm in the work-family conflict situation? Examining coping as a moderator between work-family conflict and wellbeing. International Journal of Stress Management. 2011;18(1):24.

17. Hanks RA, Rapport LJ, Vangel S. Caregiving appraisal after traumatic brain injury: The effects of functional status, coping style, social support and family functioning. NeuroRehabilitation. 2007; 22(1):43-52.

18. Lindqvist R, Carlsson M, Sjödén PO. Coping strategies and health-related quality of life among spouses of continuous ambulatory peritoneal dialysis, haemodialysis, and 
transplant patients. Journal of advanced nursing. 2000;31(6):1398-408.

19. Lilly MM, Graham-Bermann SA. Intimate partner violence and PTSD: The moderating role of emotion-focused coping. Violence and victims. 2010; 25(5): 604-16.

20. Hack TF, Degner LF. Coping responses following breast cancer diagnosis predict psychological adjustment three years later. Psycho-Oncology: Journal of the Psychological, Social and Behavioral Dimensions of Cancer. 2004;13(4): 235-47.

21. Ptacek JT, Pierce GR, Ptacek JJ, Nogel C. Stress and coping processes in men with prostate cancer: the divergent views of husbands and wives. Journal of Social and Clinical Psychology. 1999;18(3):299-324. 